\title{
Accounting based valuation formulae
}

\author{
James A. Ohlson* \\ Arizona State University \\ Alexsandro Broedel Lopes** \\ USP- Universidade de São Paulo
}

\begin{abstract}
In this paper we integrate the PVED, FCF, RIV and AEG valuation models and argue that the AEG model is practically and theoretically superior to their correspondents. We show that a firm's market price is a function of its expected earnings, short and long term growth in earnings and its cost of capital. We also comment on the empirical validity of the accounting based valuation models in Brazil.
\end{abstract}

Keywords: accounting based valuation models, PVED, FCF, RI, AEG, Brazil .

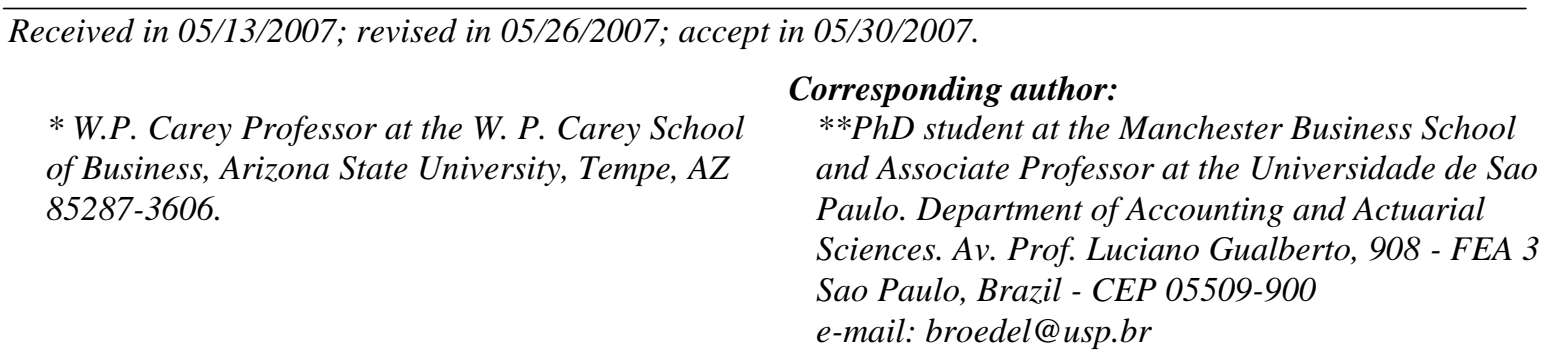

Editor's note: This paper was accepted by Arilton Teixeira. 


\section{INTRODUCTION}

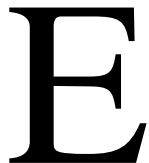

quity valuation is a topic of great interest in practice and academia. The broad issue concerns the forecasting of future expected "payoffs"; these are then converted to some intrinsic equity value via use of some discounting. In this context the word "forecasting" refers to a complex set of skills which are difficult to describe and even harder to teach, at least if the skill is to be implemented in a superior fashion. In sharp contrast, academics have much more to say about how one identifies the appropriate "payoffs" and how these are fed into valuation formulae. Students typically encounter 3 approaches to valuation: The discounting of, (i) dividends, (ii) cash flows and, (iii) residual earnings.

Practitioners of equity valuation, often to the chagrin of academics, typically rely on none of the above class-room techniques. Instead of a core organizing principle, they tend to focus on forward earnings and the growth in the subsequent expected earnings, i.e. the greater the growth, the great the price to forward earnings ratio. Exactly how such a relation actually reflects a valuation formula is more of a mystery. But as we will show in this paper, it can be developed.

This paper will show, using a relatively little known but simple technique, how one unifies various equity valuation models. The framework reconciles cash flows and residual income approaches to the more fundamental dividends approach. Moreover, we develop a formula that determines value on the basis of, (i) next-year expected eps /or "forward eps", (ii) short-term growth - - year 2 vs next-year - - in eps, (iii) long-term growth in eps and finally, (iv) the discount factor which relates directly to cost- of-capital. We will argue that the last formula is useful as it connects with analysts' concepts of how to value equities.

\section{THE VALUATION ATTRIBUTE - A QUICK REVIEW}

The theoretical starting point in equity valuation is the so-called PVED formula, i.e.

PVED stands for the present value of expected dividends:

$$
P_{0}=\sum_{t=1}^{\infty} R^{-t} d t
$$

where

$P_{0}=$ the value of equity

$R=1+r>1$ is the discount factor or 1 plus the cost-of-equity capital

$d_{t}=$ the expected dividend at date $\mathrm{t}$.

The formula raises questions about the dividend policy. Who wants to forecast dividends if the dividend policy is irrelevant? Or, stated somewhat differently, should we not focus on the value creation rather than the value distribution? Finance text-books tend to deal with these questions by introducing the present value of "free cash flows" or FCF. Specifically, the formula is:

$$
P^{0}=-D^{0}+\sum_{t=1}^{\infty} R^{-t} c
$$

where

$D_{0}=$ the debt outstanding today

$c_{t}=$ expected FCF, date $\mathrm{t}$.

Text-book often motivates this scheme by the saying "cash is king!" As a practical matter, however, "cash" is a more ambiguous concept than one might think initially. And it is not so obvious that FCF reflects value-creation, a point that accountants surely appreciate. 
To introduce accounting data as a valuation attribute, Financial Statement Analysis text-books generally introduce the so-called Residual Income Valuation, or RIV, formula:

$$
P^{0}=b v^{0}+\sum_{t=1} R^{-t} R I^{t}
$$

where

$$
\begin{aligned}
& R I_{t}=e a r_{t}-r \cdot b v_{t-1} \\
& b v_{t}=\text { expected book value, date } \mathrm{t} \\
& e a r_{t}=\text { expected earnings, period } \mathrm{t} .
\end{aligned}
$$

Experienced practitioners who happen to get exposed to this formula do not generally react favorably when it is suggested to be a useful tool: Why the emphasis on book value? In other words, it is well to note that practitioners do not start with the current book value and then try to estimate the incremental value via a forecasting of future residual earnings. In other words, what is missing is the core principle: the growth in earnings should explain the price to forward earnings ratio.

To partially address the issue of growth in earnings, text-books generally develop the so-called constant growth formula:

$$
P_{0}=\frac{e a r_{1}}{r-g} \times K
$$

where

$$
e a r_{t+1}=(1+g) \cdot e a r_{t}, t \geq 1 \text {, and the dividend payout is fixed according to } d_{t}=K \cdot e a r_{t} \text {. }
$$

But this approach is so obviously unsatisfactory that must be given short shrift. The dividend-policy is far too stringent. In addition, the same can be said for the requirement that there is one and only one growth-ratio. The near term is in this regard no different from the long term.

The state-of-the-art as described is not encouraging. What one would like to see is a unifying framework of equity-valuation, including the possibility of providing a mode of analysis that shows how the growth in expected earnings explains the $P_{0} / E_{a r}$ ratio, without placing unreasonable restrictions on the dividend policy. This approach avoids the narrowness of the traditional constant growth model. We will do so in the final part of the paper.

\section{A GENERAL FRAMEWORK FOR EQUITY VALUATION}

As always, we rely on PVED as a foundation. Thus the question becomes one of finding a scheme that gives equivalent representations, including PV of FCF and RIV.

The following scheme will prove to be exceedingly useful. Let $y_{0}, y_{1}, y_{2}, \ldots$. be any sequence of numbers, subject only to $y_{t} / R^{t} \rightarrow 0$ as $t \rightarrow \infty$ where the latter is merely a mild regularity condition. It follows immediately that

$\left.0=y_{0}+R 7^{1} y_{1}-R y_{0}\right)+R\left(\left(^{2} y_{2}-R y_{1}\right)+R\left({ }^{-3} y_{3}-R y_{2}\right)+\ldots \ldots\right.$.

Adding this expression to PVED, one obtains

$$
P^{0}=y^{0}+{ }_{t=1}^{t} R^{-t} z
$$


where

$$
z_{t}=y_{t}+d_{t}-R \cdot y_{t-1}
$$

In what follows, we have to keep in mind that the $z_{t}$-sequence depends directly on the $y_{t}$ sequence.

In applying the above mechanics, we put two central ideas into place. First, $y_{0}$ provides the starting-point in valuation. Second, we want to pick some accounting/economics constraint such that the $z_{t}$-sequence does not depend on the dividend policy. The last point is subtle: It allows us to shift the analysis away from the distribution of wealth to the creation wealth.

Next, we show how one applies the framework to the FCF and RIV approaches:

\section{A. FCF}

Put

$y_{t}=-D_{t}=$ the negative of the expected debt at date $\mathrm{t}$.

Assume further that the debt incurs an interest expense according to the equation $i n t_{t}=r D_{t-1}$. We partition activities into operating and financial activities. Thus, the balance sheet and the income statements can be summarized by

$$
\begin{aligned}
& b v_{t}=o a_{t}-D_{t} \\
& \text { ear }_{t}=\text { opear }_{t}-\text { int }_{t}
\end{aligned}
$$

where

$o a_{t}=$ operating assets net of operating liabilities, date $\mathrm{t}$

opear $_{t}=$ earnings due to operations, period $\mathrm{t}$

Define

$$
c_{t} \equiv d_{t}+i n t_{t}-\Delta D_{t}
$$

Equivalently, per text-books,

$$
c_{t}=o p e a r_{t}-\Delta o a_{t}
$$

Assume that the clean surplus relation holds, i.e. $\Delta b_{t}=e a r_{t}-d_{t}$.

With respect to $z_{t}$, one obtains

$$
\begin{aligned}
z_{t} & \equiv-D_{t}+d_{t}-R \cdot D_{t-1} \\
& =i n t_{t}+d_{t}-\Delta D_{t} \\
& =c_{t}
\end{aligned}
$$

Thus, we have identified the assumptions that equate the PVED approach to the FCF approach. Importantly, if one further assumes, reasonably, that the operating activities do not depend on the dividend policy - i.e. net borrowings can always finance a change in the dividend-policy, then $z_{t}$ does not depend on the dividend policy.

\section{B. RIV}

In this case put

$$
y_{t}=b v_{t}
$$

so that

$$
z_{t} \equiv b v_{t}+d_{t}-R \cdot b v_{t-1}
$$

Given clean surplus, it follows immediately that 


$$
z_{t}=e a r_{t}-r \cdot b v_{t-1}
$$

i.e., the PVED and RIV are identical representations of value. And, again, under the same assumption as in the previous case $(\mathrm{FCF}), z_{t}$ will not depend on the dividend policy.

We next provide the scheme that focuses on forward earnings and their subsequent growth. I will refer to this approach as the Abnormal Earnings Growth (AEG) model.

\section{AEG}

In this case put

$$
y_{t}=e a r_{t+1} / r
$$

so that

$$
\begin{aligned}
z_{t} & =\frac{1}{r}\left(e a r_{t+1}+r . d_{t}-\text { R.ear }_{t}\right) \\
& =\frac{1}{r}\left(\Delta e a r_{t+1}-r .\left(e a r_{t}-d_{t}\right)\right)
\end{aligned}
$$

One interprets $r . z_{t}$ as the expected increment in earnings, adjusted for expected earnings forgone due to the distribution of dividends. And, just like residual earnings, for a savings account $z_{t}=0$, regardless of the dividends. More generally, one sees that under two reasonable assumptions, $\partial e a r_{t+1} / \partial d_{t}=-r$ and $\partial e a r_{t} / \partial d_{t}=0, z_{t}$ does not depend on the dividend policy.

This framework would seem to be much more attractive that the RIV formula in that it focuses on next-period expected earnings, and their subsequent growth (adjusted for dividends) consistent with analysts' view of the world. We believe that RIV will never achieve the status of a premier valuation framework because it focuses, in essence, on the current book value and its subsequent growth as expressed by $z_{t}=b v_{t}+d_{t}-R \cdot b v_{t-1}$. Earnings and their growth is the name of the game, not book values and their growth. It is really that simple!

\section{A PARAMETERIZED VERSION OF THE ABNORMAL EARNINGS GROWTH MODEL}

The formula related to earnings becomes more powerful if one adds an assumption. Specifically, consider:

$$
z_{t+1}=\gamma z_{t}, t \geq 1
$$

where $\gamma \geq 1$ is some presumed growth parameter. The dynamic must also presume some initialization $z_{1}>0$. The case $z_{1}=0$ is of interest only as a benchmark; now it follows that $P_{0}=e a r_{t+1} / r$. of:

With these assumptions in place one obtains a formula that expresses value in terms

- eps $s_{1}$ : Next-year expected eps or "forward eps".

- Year 2 vs. Year 1 growth (STG) in expected eps .

- A measure of long-term growth (LTG) in expected eps .

- Discount factor which reflects risk (Cost of Equity Capital) 
Thus the investors' vision of the future is given by:

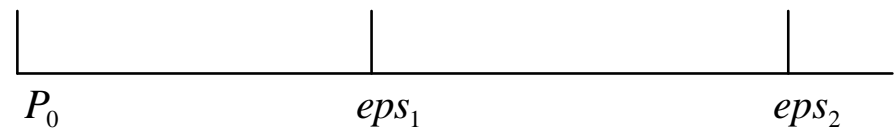

$L T G$

Some reasonably straightforward algebra results in the valuation formula

$$
P_{0}=\frac{e p s_{1}}{r} \times\left[\frac{g_{s}-g_{L}}{r-g_{L}}\right]
$$

where

$r=$ cost of capital

$g_{s}=\frac{e p s_{2}-e p s_{1}}{e p s_{1}}+\frac{r \times d p s_{1}}{e p s_{1}}$

and

$g_{L}=\frac{e p s_{t}-e p s_{t+1}}{e p s_{t-1}}$ as $t \rightarrow \infty$ (assuming full payout) $\equiv L T G$

Note that the correction to the short-term growth in eps, namely the term $r \times d p s_{1} / e^{e p s_{1}}$ is typically small compared to $\Delta e p s_{2} /$ eps $s_{1}$. This term reflects the foregone year 2 earnings due to the distribution of wealth at the end of year 1 .

In the very long run one can expect all firms to be identical. Hence, one can reasonably suggest that $g_{L}$ is the same for all firms and the quantity will approximate the steady state growth of GNP such as $3-4 \%$. But this thinking also imposes a straight jacket. More generally one can view $r$ as a LTG-parameter that differs across firms and industries.

Every valuation formula leads to the familiar problem that the discount factor is not a "known quantity". Because of this somewhat grim reality, practical analysis engages in "reverse engineering". That is, one can take the current equity value, $P_{0}$,

as a given and solve for $r$. In the present case one obtains the following square root formula:

$$
r=A+\sqrt{A^{2}+{ }_{F_{0} p s_{1}} \times\left(\begin{array}{c}
\Delta e p s_{2} \\
e p s_{1}
\end{array}-(\gamma-1)\right)}
$$

where

$$
A \equiv \frac{1}{2}\left(\gamma-1+\frac{d p s_{1}}{P_{0}}\right)
$$

and

$$
1 \leq \gamma<R
$$

We believe this formula will be useful in practice and research. Specifically, $r$ serves as an indicator of the following possibilities:

(i) A firm's risk

(ii) An indication that $e p s_{1}$ is not what the market really believes in pricing the security. That is if $r$ is high - - which makes the stock look "cheap" - - then, $e p s_{1}$ will be revised downward in the near future 
(iii) A firm's equity is mispriced and thus it potentially leads to an attractive investment opportunity.

More generally, we note that the valuation approach that focuses on earnings and their subsequent expected growth has a number of attractive features. Simple assumptions result in a formula expressing value as a function of four variables: (i) next year estimated eps (ii) short term eps growth (iii) long term eps growth and (iv) cost of capital. The valuation formula is easy to implement using eps forecasts. The valuation implies that $P_{0} /$ eps increases if (i) short-term eps growth increases (ii) long-term eps growth increase and (iii) the cost-ofcapital decreases. The valuation formula allows short-term eps growth to exceed cost-ofcapital. The valuation formula is consistent with the fact that the $P_{0} /$ ratiogenerally eps $s_{1}$

exceeds the inverse of the cost-of-capital. The "square-root" formula derives a firm's expected market return; it depends only on (i) $P_{0} / e^{e p s_{1}}$, (ii) the $d p s_{1} / P_{0}$ ratio, (iii) short-term eps growth and, (iv) long-term eps growth.

\section{EMPIRICAL EVIDENCE ON ACCOUNTING BASED MODELS IN BRAZIL}

In the last few years we have seen an upsurge in the popularity and use of accounting based valuation models in Brazil. At least in academia these models are gaining momentum and turning to be the benchmark in financial accounting research. Starting with the pioneering works of Lopes $(2001 ; 2005)$ a significant strand in the literature has evolved. Lopes (2001) has shown the superiority of RIV models over PVED and that most of the value relevance of accounting numbers is concentrated on book values which confirms hypothesis raised by Piotroski (2000) about distressed firms. More recently Lopes and Galdi (2007) have shown that fundamental analysis based on high book-to-market firms provide abnormal returns adding more light in this matter. These papers also provided empirical support for the convergence of RIV and FCF models under very limiting conditions. The AEG model has also been tested and their validity proved.

This mounting evidence points to the usefulness of accounting reports under very inimical circumstances. Brazilian accounting numbers are generally considered to be uninformative (Lopes and and Walker, 2007; Lopes, 2006) and its financial markets are dominated by macroeconomic instability. The evidence that accounting based valuation do work on such circumstances add a lot to our knowledge of their validity and usefulness. Further research is needed to improve our understanding of the role played by institutional and firm-level variables on the relevance of accounting for equity valuation.

\section{CONCLUDING REMARKS}

In our minds, the simple points serve the useful purpose of unifying valuation across different approaches. Staring from PVED it becomes straightforward to show how one derives PV of FCF, Residual Income Valuation and, not the least, the Abnormal Earnings Growth approach. Further, with the latter framework in place, one can add a growth assumption to obtain a formula that works as an approximation of the "real world": The price to forward earnings can be explained by the subsequent growth in expected earnings -- LTG as well as STG -- without imposing an unpalatable assumption on the payout ratio. 


\section{REFERENCES}

Lopes, A. B. 2001. A relevância da Informação Contábil para o Mercado de Capitais: o modelo de Ohlson aplicado à BOVESPA. PhD Disertation. Universidade de Sao Paulo, Brazil.

Lopes, A. B. 2005. Financial Accounting in Brazil: an Empirical Examination. Latin American Business Review 6, p. 45-68.

Lopes, A. B. 2006. Empirical Evidence on the Relation Between Revaluations of Fixed Asset and Future Firm Performance in Brazil. In: GREGORIUS, G, and GRABER, M. (Org.). International Accounting: Standards, Regulations and Financial Reporting. Elsevier.

Lopes, A. B., Galdi, F.C. 2007. Does Financial Statement Analysis Generate Abnormal Returns under Extremely Adverse Conditions? Annual Meeting of the American Accounting Association, Chicago Illinois.

Lopes, A. B., Walker, M. 2007. The Relation Between Firm-Specific Corporate Governance, Cross Listing and the Informativeness of Accounting Reports. Working paper. Manchester Business School.

Piotroski, J.D. 2000. Value Investing: The Use of Historical Financial Statement Information to Separate Winners from Losers. Journal of Accounting Research 38, p. 1-41. 